\title{
Epidemiology, genetics and management of psoriatic arthritis 2013: focus on developments of who develops the disease, its clinical features, and emerging treatment options
}

REVIEW

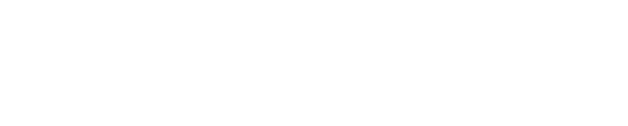

\author{
Muhammad Haroon' \\ Oliver FitzGerald' \\ Robert Winchester ${ }^{2}$ \\ 'Department of Rheumatology, \\ St Vincent's University Hospital, \\ Dublin, Ireland; ${ }^{2}$ Division of \\ Rheumatology, Columbia University \\ College of Physicians and Surgeons, \\ New York, NY, USA
}

\begin{abstract}
The picture of elements comprising the genetic susceptibility to develop psoriatic arthritis, especially those involving human leukocyte antigen alleles, is emerging in much greater clarity because of improvements in the methods of psoriatic arthritis ascertainment and in the technology of genetic typing. This new knowledge suggests there is genetic heterogeneity in the psoriasis phenotype, and that there are several genetically and clinically different forms of psoriatic arthritis. These genetic studies on psoriatic arthritis further reinforce the relationship of psoriatic arthritis to the other spondyloarthritides, but also raise novel questions of whether the effect of certain susceptibility genes may differ among them. Considerable evidence indicates that the clinical features reflect a CD8 T lymphocyte-driven immune response is present that is characterized by clonal expansion and differentiation towards memory-effector phenotypes. With the aid of new classification criteria, the typical clinical features of psoriatic arthritis involving different joints, entheses, and their related compartments are being better defined as distinctive characteristics of psoriatic arthritis or of the spondyloarthritis group of disorders. In the evaluation of an individual with psoriatic arthritis, taking a patient-focused perspective is recommended, which has the potential to enhance their quality of life significantly. The choice of current and emerging therapeutic agents from an increasing realm of conventional and biologic agents is becoming much better rationalized and more firmly based on evidence from clinical trials.
\end{abstract}

Keywords: psoriatic arthritis, genetic susceptibility, heterogeneity, classification, diagnostic criteria, treatment

\section{Introduction}

Consistent progress has been made in multiple areas of the understanding of psoriatic arthritis (PsA) and in the approach to the diagnosis and therapy of this disease. The picture of elements comprising the genetic susceptibility to develop PsA, especially those involving Human leukocyte antigen (HLA) alleles, is emerging in much greater clarity because of the improvements in PsA ascertainment and in the technology of genetic typing. It is becoming evident that psoriasis in general and PsA in particular is not a homogeneous phenotype determined by the same susceptibility genes. This suggests that there are several genetically and clinically different forms of PsA. HLA and likely other genes play a role both in determining disease susceptibility and in determining the particular constellation of clinical findings a patient will exhibit. The clinical features comprising PsA are being better delineated, leading to improved classification and diagnostic criteria. The improved imaging methods of ultrasound
Correspondence: Robert Winchester Division of Rheumatology, Department of Medicine, Columbia University College of Physicians and Surgeons, 630 West 168th Street, New York, NY 10032, USA Email rjw8@columbia.edu 
and magnetic resonance imaging (MRI), which delineate features of inflammation better than conventional X-rays, are also providing much greater insight into the disease and improving its differentiation from other forms of inflammatory arthritis. The outlook for effective therapy is steadily improving, although the newer genetic and pathogenic insights are only beginning to drive progress towards novel therapies specific for the inflammatory mechanisms underlying PsA. This review highlights some of these new insights into PsA, and attempts to integrate them into an improved understanding and approach to this disease.

\section{Genetic epidemiology}

The estimated prevalence of PsA in the general population is still a subject of study, but using the newer classification criteria, it ranges from $0.16 \%$ to $0.25 \%,{ }^{1,2}$ while the prevalence of psoriasis is 10-20 times greater. ${ }^{1}$

A striking feature of PsA is its remarkably strong familial aggregation. The early studies of Moll and Wright ${ }^{3}$ noted $5.5 \%$ of first-degree relatives were affected, allowing calculation of a recurrence risk ratio in first-degree relatives $(\lambda 1)$ of $55 .{ }^{4}$ A more recent study reported similar results. ${ }^{5}$ Interestingly, in contrast, the comparable risk ratio in psoriasis is in the range of 5-10, reflecting a much lower overall heritability. ${ }^{4}$

\section{HLA alleles and PsA susceptibility}

While we still do not have a complete description of the genes specifying PsA susceptibility, earlier studies in $\mathrm{PsA}^{6}$ using less sophisticated technology were motivated by the central function played by HLA polymorphisms in the genesis of the adaptive immune response in other autoimmune diseases, and established HLA class I polymorphisms as the major candidate genes for PsA susceptibility. These earlier studies identified associations with particular HLA alleles or their haplotypes, and provided important evidence indicating that the immune response in PsA exhibits the HLA genetics typical of an adaptive immune response. However, the magnitude of the observed associations were inconstant and left numerous questions unanswered.

The meaning of these HLA associations in PsA is based on the fundamental role of HLA molecules during development of the immune system; the binding of self-peptides to HLA (major histocompatibility complex [MHC]) molecules results in the selection of the individual's self-specific T-cell repertoire. ${ }^{7}$ Largely in response to pathogen-driven selection, the number of MHC alleles has increased enormously. ${ }^{8}$
These alleles, identified through advances in DNA technology, are distinguished by amino acid polymorphisms in pockets that confer the specificity to bind the side chains of particular peptides derived from different self-peptides. The advantage to the species that results from this large number of HLA allotypes is the ability to thwart epidemics of a particular pathogen, since as a result of being selected on different self peptides, the $T$ cells of each individual's immune system encountered by the pathogen are capable of recognizing different pathogen structures. However, an untoward aspect of the pathogen-mediated diversification of $\mathrm{MHC}$ alleles is that certain allotypes bind different self-peptides that are from target tissues, and that recognition by one's own T cells of these self-peptides sets the stage for the development of an autoimmune disease.

A more recent group of studies of the HLA polymorphisms in $\mathrm{PsA}^{9,10}$ has resulted in a substantial change in the conceptual basis of PsA. These studies were distinguished by: (a) more precise methods of allele determination, including sequence-specific oligonucleotide probes and sequencebased typing, which are a marked improvement over less precise serologic techniques; (b) study designs that directly ascertain PsA cases based on current criteria and compare these with psoriasis cohorts selected for the absence of arthritis; and (c) perhaps most importantly, greatly improved case ascertainment resulting from the application of the more precise Criteria of the ClASsification of Psoriatic ARthritis (CASPAR) or analogous criteria.

The general insights emerging from these studies are: (a) PsA is seen as more closely related to the other spondyloarthritides; (b) the MHC genetics of PsA fundamentally differ from those of psoriasis, although there is some overlap in those with $H L A-C^{*} 06: 02$; (c) they downplay the significance of a unitary cutaneous psoriasis phenotype in PsA, with the older "disease within a disease" paradigm of psoriasis as the parent entity and PsA as a subset being increasingly seen as having only limited productivity, although aspects of psoriasis pathogenesis in PsA partially overlap; (d) PsA is itself heterogeneous; and (e) genes involved in determining PsA susceptibility also specify different clinical phenotypes, likely reflecting pathogenic mechanisms directed against different peptides. The evidence supporting these conclusions will be briefly reviewed.

\section{Psoriasis as the starting point and the role of $C^{*} 06: 02$ in psoriasis susceptibility}

Since the presence of cutaneous psoriasis was a critical feature that led to the definition and redefinition of PsA, 
the well-characterized genetics of cutaneous psoriasis in the absence of PsA remains the starting point. In psoriasis, HLA-C*06:02:01:01 (HLA-C*06:02), previously termed HLA-Cw6, is present in $\sim 60 \%$ of cases of type I psoriasis (with onset before age 40 years), ${ }^{11,12}$ and recombinant haplotype-mapping studies have identified $H L A-C * 06: 02$ as the major genetic determinant of susceptibility to psoriasis. ${ }^{13,14}$ The current studies of PsA susceptibility having psoriasis control cohorts find the same values for the frequency of $H L A-C^{*} 06: 02$, eg, $57.5 \% .^{9}$

\section{The representation of HLA-C*06:02 in PsA}

In PsA cases, an increase in the frequency of $H L A-C^{*} 06: 02$ has also long been reported. ${ }^{15}$ However, there was considerable disagreement about the extent of the increase. ${ }^{4,6,16,17}$ In some reports, the frequency of $H L A-C * 06: 02$ is equivalent to levels found in psoriasis $-56 \%$ and $60 \%{ }^{18,19}-$ a level of increase that would support the hypothesis that PsA and psoriasis are a genetically homogeneous entity. In contrast, others report much lower frequencies of HLA-C*06:02 in PsA, ${ }^{20-23}$ more consistent with genetic heterogeneity. Since genetic heterogeneity of MHC susceptibility alleles suggests different peptides are recognized in different autoimmune responses, with potentially distinct clinical and therapeutic implications, the extent to which the MHC alleles of PsA resemble those of psoriasis is an important concern.

In our study of PsA, we examined the genetic heterogeneity of PsA and the psoriasis phenotype, with specific attention to disease ascertainment, ethnic stratification, and precise allele typing. ${ }^{9}$ The answer to the question of to what extent does the MHC contribution to PsA susceptibility resemble that of cutaneous psoriasis, was that in PsA cases presenting to a rheumatology unit, the frequency of $H L A-C^{*} 06: 02$ was $28.7 \%$, a value that was significantly lower than in the psoriasis cohort $\left(57.5 \%, P=9.9^{-12}\right)$. This heterogeneity in MHC genes between the cohorts allowed rejection of the hypothesis that the psoriasis phenotype is genetically homogeneous, and we conclude that the psoriasis phenotype and specifically PsA is genetically heterogeneous. This finding also establishes one subset of PsA cases, accounting for slightly more than a fourth of the cases, is related to psoriasis cases defined by the presence of $C^{*} 06: 02$. The remaining PsA cases are clearly members of an entity fundamentally different from that of the psoriasis cases defined by the presence of $H L A-C^{*} 06: 02$, although they share the generic psoriasis phenotype.

\section{Role of additional HLA alleles in PsA susceptibility, which are not significant components of psoriasis susceptibility}

Additional MHC allele families $H L A-B * 27$ and $H L A-B * 39$, which also play a well-recognized role in susceptibility to ankylosing spondylitis (ASp), have also been implicated in PsA susceptibility. $B * 27$ was first found elevated, ${ }^{24}$ but subsequently the frequency, as determined serologically, ranged from not increased over controls to as high as 39\%, reviewed in Winchester. ${ }^{6}$ In marked contrast, in psoriasis, $H L A-B * 27$ has only occasionally been reported as significantly but slightly increased. ${ }^{25,26}$ The increased frequency of $H L A-B * 39$ in PsA was also detected serologically. ${ }^{17,27,28}$ The serologic $H L A-B * 39$ allele group contains 57 allelic subtypes that differ in their coding regions, as shown by DNA sequencing. Of these, the two most common alleles in the Irish study population are $B * 39: 06: 01$ (henceforth $B * 39: 06$ ) and $B * 39: 01: 01: 01$ (henceforth $B * 39: 01$ ), present on two haplotypes, respectively either in linkage disequilibrium with $C^{* 07: 02: 01 ~(E H 39.7) ~ o r ~} C^{*}$ 12:03:01:01 (EH39.1) (henceforth $C^{*} 07: 02$ and $C^{*} 12$ ). The structurally related $B * 38$ allele group has also been reported to be elevated in PsA in some, but not other studies. ${ }^{15,17,27-29}$ The most common $B * 38$ haplotype, $E H B 38.1$, contains $B * 38: 01: 01$ (henceforth $\left.B^{*} 38\right)$ and $C^{*} 12$.

Three haplotypes containing $B^{*} 27$ or $B * 39: 01$ were significantly increased in frequency in the PsA cohort, 15.6\% versus $5.5 \%$ in reference controls, but were not increased in the psoriasis cohort (4.7\%). ${ }^{9}$ Since the EH27.1 and EH27.2 haplotypes associated with PsA susceptibility share the same $B * 27$ allele but differ in their $H L A-C$ alleles, this strongly suggests this susceptibility maps to the $H L A-B$ locus and to the $B * 27$ allele itself. Furthermore, the structural and functional similarities between the molecules encoded by $B * 39: 01$ and $B * 27$ also point to a role of the $H L A-B$ alleles. Both alleles encode electronegative $\mathrm{B}$ pockets, ${ }^{30}$ which bind positively charged arginine anchor motifs at position $\mathrm{P} 2,{ }^{31,32}$ a feature proposed to explain their role in ASp susceptibility. ${ }^{33,34}$ Furthermore, they share cysteine 67 , a residue hypothesized to play a role in ASp by forming $\alpha$-chain homodimers. ${ }^{35-37} B * 38: 01$, also present on a haplotype with $C^{*} 12$, was marginally significantly increased, indicating it is also implicated in PsA susceptibility but contributes more weakly to susceptibility. The lower frequency of the susceptibility alleles $B * 27$ and $B * 39$ in the general population, compared to that of $C^{*} 06$, and the milder skin disease associated with $B * 27$ appear to account for the minimal impact of these allotypes on psoriasis. 


\section{HLA-B*27 and HLA-B*39 molecules share affinity for similar peptides}

Reflecting the specificity of the association, among the haplotypes containing members of the $H L A-B * 39$ family of alleles, we found that only EH39.1, which contains $B^{*} 39: 01$, and $C^{*} 12$, was associated with PsA susceptibility, even though $E H 39.7$ was found in the control population at a nearly equivalent frequency to EH39.1. This striking contrast emphasizes that specific features of EH39.1 are responsible for susceptibility. $E H 39.7$ contains $B^{*} 39: 06$ and $C^{*}$ 07:02, and the $\mathrm{B} * 39: 01$ and $\mathrm{B} * 39: 06$ molecules differ at L95W and R97T, likely affecting binding pockets towards the $\mathrm{C}$ terminus of the peptide. ${ }^{9,31,32}$ EH38.1 exhibited an inconstant contribution to PsA susceptibility in our study, compared to the stronger contribution of $B^{*} 39: 01$. EH38.1 shares $C^{*} 12$ with $E H 39.1$, and $B^{*} 38$ a B pocket generally similar to the $B * 39: 01$ product, but differs in its preferences for histidine and not arginine, and for a negatively charged residue at position 3, suggesting that $B * 39: 01$ and $B * 38: 01$ preferentially bind different peptides. The molecule encoded by shared $H L A-C^{*} 12$ alleles could be an alternative explanation, however the $\mathrm{B} 18$ allele, which is also present on a $C^{*} 12$ haplotype, is not increased in frequency in PsA: $5.8 \%$ versus $6.1 \%$ in reference controls. ${ }^{9}$

\section{Influence of HLA alleles on the risk of an individual with psoriasis to develop PsA}

The likelihood of a person progressing to PsA if they present with psoriasis can be estimated by comparing the prevalence of psoriasis to PsA, assume 10:1, and the relative frequency of the allele in the two populations. ${ }^{9}$ For $H L A-C^{*} 06: 02,5 \%$ of those with psoriasis will be expected to develop PsA; in contrast, $28 \%$ and $33 \%$ of those with $B^{*} 39$ or $B^{*} 27$ and psoriasis are expected to have or to develop PsA, reflecting the greater penetrance of the musculoskeletal phenotype in the latter alleles.

\section{Alleles marking decreased susceptibility to PsA}

In HLA association studies of most autoimmune diseases, certain alleles are significantly underrepresented in the disease cohort, which is consistent with the interpretation that these alleles exhibit a "protective" effect. $B^{*} 40$ and $B * 44: 02$, and their haplotypes EH40.1, EH44.5, and EH44.7, are decreased in frequency in the PsA cohort, suggesting they might diminish PsA susceptibility; however, $B * 44: 03$ was not similarly associated, emphasizing the impact on susceptibility of specific alleles. ${ }^{9} H L A-B * 40$ was previously identified as specifying a decreased risk for developing psoriasis. ${ }^{38}$ Intriguingly, the $B * 40$ and $B * 44: 02$ molecules share similar electropositive $B$ pockets and prefer binding peptides with negatively charged glutamic acid anchor residues at $\mathrm{P} 2,{ }^{32}$ the exact opposite to the specificity pattern of the $B * 39: 01$ and $B * 27$ susceptibility molecules. The probability of selecting two alleles by chance that encode the same type of glutamic acid-binding B pocket, opposite in charge to amino acids preferentially bound by the $B * 27$ and $B * 39$ susceptibility allele products, is $P=0.0025$. These findings argue in support of the interpretation that B*39:01 and $B * 27$ susceptibility molecules operate in the pathogenesis of PsA through their binding and presentation of self-peptides. We conjecture that the "protective" effect of alleles conferring decreased susceptibility to PsA operates during thymic selection of the individual's T-cell repertoire, perhaps acting to delete T-cell clones that otherwise would mediate development of PsA.

\section{Clinical phenotype and genetics: $H L A-B * 27$}

Since the initial study by Brewerton et al, ${ }^{24} H L A-B * 27$ has been proposed as being linked to the presence of spondylitis in PsA, but in subsequent studies this association has been inconstant. ${ }^{39-43}$ Analogously, HLA-C*06:02 has been reported to be associated with fewer involved or damaged joints. ${ }^{44}$

In an analysis of the Irish cohort, several features of association of clinical phenotype are emerging, which may shed light on the conflicting results. The first point that appeared relatively well etched was that the interval in years between the onset of psoriasis and the development of PsA was a quantitative phenotypic trait that was determined in part by HLA type. ${ }^{9}$ Nearly half, $47.6 \%$, of $H L A-B * 27$ cases, independent of whether they were EH27.1 or EH27.2, had the onset of psoriasis either after the onset of musculoskeletal disease, or roughly contemporaneously. In contrast, only $20.4 \%$ of $H L A-C^{*} 06: 02$ PsA cases had a similar onset pattern. The proportion of $H L A-B * 27$ cases in the group presenting as PsA before or contemporaneously with the onset of psoriasis exceeded the proportion of $H L A-C^{*} 06: 02$ PsA, while in the subset of cases with $>15$ years between the onset of psoriasis and that of PsA, the frequency of $H L A-C^{*} 06: 02$ PsA was sevenfold greater than that of $H L A-B * 27$.

These data suggest that two separate principal patterns of MHC effect will result in the psoriasis phenotype. The first involves the classic psoriasis susceptibility gene 
$H L A-C^{*} 06: 02$, and is characterized by more penetrant skin disease with less prevalent and more time-dependent development of the musculoskeletal phenotype. The second appears to be mediated by alleles of the $H L A-B$ locus, including $B^{*} 27$ and $B * 39$. This latter pattern includes a musculoskeletal phenotype nearly equivalent in penetrance to that of the skin disease, and in the case of $H L A-B * 27$, occurs temporally much more coincident with musculoskeletal involvement.

Additional studies on the relationship between phenotype and genotype disclose an interesting divergence between the two $\mathrm{B} * 27$ haplotypes. The $H L A-B * 27-C * 01$ haplotype (EH27.1) is positively associated with more severe peripheral joint disease, as shown by the number of erosions and the requirement for anti-tumor necrosis factor (TNF) therapy. ${ }^{45}$ Similarly, an axial phenotype including spine and sacroiliitis (SI) disease is predominant. In contrast, $H L A-C^{*} 06: 02$ haplotypes (EH57.1, EH37.1, EH13.1) are negatively associated with these same features.

Intriguingly, the $H L A-B^{*} 08-C^{*} 07$ haplotype (EH08.1) is positively associated with more severe peripheral joint disease, including deformity, erosion, requirement for TNF therapy, dactylitis, and osteolysis. However, similarly to $H L A-$ $C^{*}$ 06:02 haplotypes, arthritis onset is delayed multiple years after onset of psoriasis. Indeed, the inheritance of $E H 27.1$ or EH08.1 or HLA-C*05 almost completely predicts the occurrence of SI in PsA, while the occurrence of erosions in PsA is almost completely predicted by the inheritance of $E H 27.1$ or EH08.1 or HLA-C*03. The involvement of EH08.1 appears to act independently in denoting a particular phenotype of severe disease from other susceptibility haplotypes.

Interestingly, when $B * 27$ was found on the $E H 27.2$ haplotype, there were no significant phenotypic associations. This indicates that $B^{*} 27$ by itself does not account for the disease phenotype, and that another hypothetical gene in linkage disequilibrium with $B * 27$, which is present on the EH27.1 haplotype, is responsible, acting either independently or in concert with $B * 27$. This haplotype dependence of clinical phenotype may be a factor in explaining the divergence of associations with $B * 27$ in different series.

\section{Relationship of PsA to the other spondyloarthritides}

An additional outcome of the recent HLA studies on PsA is to further reinforce the relationship of PsA to the other spondyloarthritides. The elevation in frequency of $B^{*} 27$ and $B * 39: 01$ and the molecular similarities of these allotypes support the clinical relationship between PsA and ASp.
However, there are certain clear differences that suggest that the mechanism of action of $B * 27$ could differ in the two diseases. First, compared to ASp, the overall proportion of PsA cases attributed to $B * 27$ is much lower. In the instance of ASp, it is $\sim 95 \%$, while only $15 \%-20 \%$ in PsA. Second, the proportion of $B^{*} 39: 01$ to $B^{*} 27$ is $\sim 1: 3$ in PsA and $\sim 1: 20$ in ASp. These two features of differing $B * 27$ frequency suggest that the peptide-binding attributes of $\mathrm{B} * 27$ and $\mathrm{B} * 39$ may predominate in PsA, whereas the $(\mathrm{B} 27)_{2}$ or other physicochemical attributes of the $\mathrm{B} * 27$ molecule predominate in ASp. Third, the musculoskeletal phenotype of the PsA cases inheriting $H L A-B * 27$ is not a precise copy of the ascending spondylitis and large peripheral joint involvement characteristic of ASp. Lastly, ASp is not increased in frequency in the setting of advanced AIDS, in marked contrast to the increased prevalence of PsA, reactive arthritis, and undifferentiated forms of spondyloarthritis. ${ }^{46}$ Together, these findings suggest that the mechanism of action of $B * 27$ could differ in these two forms of spondyloarthritis.

\section{Pathogenesis: immunologic background}

Considerable evidence indicates that a CD8 T lymphocytedriven immune response is present in PsA that is characterized by clonal expansion and differentiation towards memory-effector phenotypes. These are the predominant cellular infiltrates in the epidermis, synovial fluid, and enthesis. ${ }^{47-50}$ The earlier evidence that there is skin-specific migration of $\mathrm{CLA}^{+} \mathrm{T}$ cells that do not similarly accumulate in the joints of PsA cases was an important finding that foreshadowed the divergence between psoriasis and PsA..$^{51}$ In the synovium itself, there is reduced synovial membrane macrophage numbers, endothelial-leukocyte adhesion molecule 1 expression, and lining-layer hyperplasia in PsA compared with rheumatoid arthritis. ${ }^{52,53}$

From the above genetic data, we hypothesize ${ }^{9}$ that presentation of self-peptides by MHC molecules encoded by $H L A-B * 27$ or $B * 39$ alleles establishes a T-cell repertoire that gives rise to an autoimmune response equally focused on antigens in the musculoskeletal system that are shared with the skin, in contrast to the primary response to a cutaneous antigen mediated by the different peptide-binding properties of $C^{*}$ 06:02 molecules, which only much later and in a small proportion of cases spreads to involve a musculoskeletal antigen. Accordingly, the $\mathrm{T}$ cells mediating the pathogenic processes in PsA would be expected to be CD8 lineage and memory effector in their phenotype. Another major clinical clue pointing to the role of memory-effector $\mathrm{CD} 8 \mathrm{~T}$ cells in PsA was provided by the de novo development of PsA 
in the setting of the profound CD4 T-cell depletion induced by advanced HIV infection and AIDS. ${ }^{46}$ Persistent bacterial infections, often including arthritogenic organisms like Salmonella sp and the elevated cytokines of AIDS provided the optimal environment for activating CD8 memory-effector T cells.

In terms of the function of the particular memory-effector phenotypes, PsA was classically considered a Th1-mediated disease; however, the identification of the Th17 subset has substantially changed the general concepts of how autoimmune inflammation is mediated. The secretion of interleukin (IL)-17 by Th17 cells establishes an inflammatory pathway that results in the production of IL- 1 and TNF- $\alpha$. In view of the major role of IL-23R engagement by IL-23 for the expansion and activation of the Th17 subset, it is intriguing to note that susceptibility to both psoriasis or PsA is significantly associated with alleles of the $I L 23 R$ gene. ${ }^{54,55}$ In an interesting murine model of enthesitis, it was recently shown that IL-23 activates resident T cells within the mouse enthesis and in the aortic root. ${ }^{56}$ These activated $T$ cells can then promote local inflammation and new bone formation through a variety of effector mediators, including IL-17 and IL-22. The resident T cells have the unusual phenotype of $\mathrm{CD}^{+}{ }^{+} \mathrm{CD} 4^{-}{ }^{-} \mathrm{D} 8^{-} \mathrm{IL}-23 \mathrm{R}^{+} \mathrm{ROR}-\gamma \mathrm{t}^{+}$, where ROR- $\gamma \mathrm{t}$ is the retinoic acid receptor ( $R A R$ )-related orphan receptor $\gamma t$ (ROR $\gamma t$ is a novel isoform of the orphan nuclear receptor ROR $\gamma$ ). The $\mathrm{CD}^{-}$phenotype of these T cells distinguishes them from Th17 $\mathrm{T}$ cells. This finding opens the study of a potential novel effector pathway for mediating the changes of enthesitis and features of ASp. However, additional work will be required to relate this provocative finding to PsA, and in particular to determine whether it might also contribute to the different phenotypes associated with $H L A-B * 27$ and $H L A-C^{*} 06: 02$, which as outlined above differ in a number of particulars from ASp.

\section{Disease manifestations and relationship to diagnostic criteria Signs and symptoms}

Being a progressive inflammatory joint condition, PsA usually causes pain and joint damage, eventually leading to disability. The following are typical clinical symptoms of PsA involving different joints and their related compartments, which are being better defined as distinctive characteristics of PsA or the spondyloarthritis group of disorders. It is not uncommon that the diagnosis of PsA is often missed in primary care physicians' and dermatologists' offices. An obvious reason is that rather than presenting with florid active polyarthritis, a number of patients with PsA present with inflammatory spinal pain, tendinitis, enthesitis, or dactylitis. Many classification criteria of PsA have been proposed, but CASPAR criteria are now the most commonly used and internationally agreed criteria. ${ }^{57}$

\section{Dactylitis}

In dactylitis, there is usually diffuse inflammation of the tendons, entheses, and synovium of nearby joints occurring simultaneously, leading to the typical "sausage" appearance. Multiple studies using sensitive imaging modalities have shown that flexor tenosynovitis is the key finding, and the joint capsule distention is seen in only a minority of cases. ${ }^{58,59}$ It is reassuring that physical examination has shown $100 \%$ sensitivity and specificity compared to MRI findings to diagnose tenosynovitis. ${ }^{58}$ Dactylitis is observed in all forms of spondyloarthropathies, with significant specificity in PsA, and this has been included in the classification criteria of PsA, eg, CASPAR criteria. ${ }^{57}$ Dactylitis can be present in up to $48 \%$ of patients with PsA, ${ }^{60,61}$ where this can be the first presentation of PsA, and for some time can remain the sole manifestation of this disease. This usually involves toes more than fingers in asymmetrical distribution, and leads to more severe radiological damage. ${ }^{61}$

\section{Peripheral arthritis and spondylitis}

Psoriatic arthritis can generally affect any joint in the body. Typically, it affects large joints of the lower extremities, distal joints of the fingers and toes, and cervical spine and sacroiliac joints. Classically, the tenderness and joint effusion are less severe than in rheumatoid arthritis (RA). The original diagnostic criteria of Moll and Wright describe five clinical patterns of PsA, which can evolve from one to another: ${ }^{62}$

- asymmetrical monoarticular and oligoarticular arthritis

- symmetrical polyarticular arthritis

- distal interphalangeal joint involvement

- arthritis mutilans

- axial or spondylitis type.

The original studies by Moll and Wright described asymmetrical oligoarthritis as the most frequent clinical pattern of PsA; however, CASPAR database analysis does not support this statement, and the authors conclude that the symmetric polyarticular pattern is the most common presentation. ${ }^{63}$ Moreover, the authors suggest that articular disease in PsA should be classified as either axial and/or peripheral, and the polyarthritis subgroup of PsA has a number of similarities with the nonpolyarticular subgroup of PsA. 
About $20 \%$ of people who develop PsA will eventually have spinal involvement, known as psoriatic spondylitis. This spinal inflammation can either lead to complete fusion, as in ASp, or skip areas where, eg, only the lower back and/or neck are involved. Those with spinal involvement are most likely to test positive for HLA-B*27. The spondylitis symptoms typically include pain and stiffness in the area of the lower back, neck, ribs, hips, and thighs. The Assessment of the Spondyloarthritis International Society inflammatory back pain criteria can be helpful to identify such patients, which include age at the onset of back pain $<40$ years, insidious onset, improvement with exercise, no improvement with rest, and nocturnal pain; inflammatory back pain is present if any four out of these five features are present. ${ }^{64}$ It is quite common that clinical evidence of spondylitis and/or SI occur in conjunction with other subgroups of PsA. Additionally, the spondylitis may even be asymptomatic, and there may be absence of typical radiologic features of SI, which frequently tends to be asymmetrical. In other words, there can be a poor correlation between symptoms and radiologic signs of SI.

\section{Enthesitis}

Entheses are the sites of bony attachments of joint capsules, ligaments, and tendons. Inflammatory changes at these sites (enthesopathy) are the leading manifestation of disease in patients with inflammatory SpA. They are most commonly found at the insertions of the Achilles tendon and the plantar fascia, but may occur in other sites, such as spine and pelvis, femoral trochanter, humeral epicondyles (commonly known as tennis elbow or golfer's elbow), tibial tuberosity, patella, and olecranon. To examine an entheseal site, sufficient pressure is exerted to blanch the fingernail of the examiner (approximately $4 \mathrm{~kg}$ ). The Leeds Enthesitis Index is a simple scoring system that is commonly used for assessments of entheses. The entheseal sites included in the Leeds Enthesitis Index are: bilaterally, the lateral epicondyle of the humerus at the common extensor origin, the medial condyle of the femur just superior to the joint line, at the origin of the medical collateral ligament, and the posterior prominence of the calcaneum at the insertion of the Achilles tendon. The soft-tissue components of an enthesis are traditionally evaluated by clinical examination based on the presence of tenderness and/or swelling, while X-rays have been used to assess associated bony changes. Enthesitis may be recognized radiographically as spurs and may also be identified using ultrasound scan. MRI scan reveals bone marrow edema adjacent to the entheseal insertion sites, representing a synovio-entheseal inflammatory complex at the very early stage of PsA,${ }^{65}$ which supports the hypothesis that entheseal inflammation is the prime or initial target in PsA disease pathogenesis. For each entheseal site, an assessment of the adjacent joint in terms of tenderness and soft-tissue swelling should be made in order to distinguish the swelling and tenderness separately at the joint and the juxta-articular enthesis.

\section{Diagnosis of psoriasis arthritis}

Currently, there is no single diagnostic laboratory test for PsA. A thorough physical exam including X-rays and individual medical history, as well as blood work including a negative test for rheumatoid factor, is helpful in making a diagnosis. Acute-phase reactants in PsA are frequently normal or minimally elevated, contributing little to diagnosis, and at times can unfortunately lead to a delayed referral. Positive serology for anti-cyclic citrullinated peptide antibodies, though more prevalent in RA, may be found in $10 \%-15 \%$ of PsA patients; ${ }^{66}$ moreover, its presence has been associated with not only more swollen and tender joints but also with more deformed and erosive arthritis. ${ }^{67}$ There are no proven blood biomarkers for predicting the diagnosis of PsA. Typical radiological features of PsA include pencil-in-cup appearance, irregular periosteal bone proliferation, resorption of the distal tuft, and ankylosis. ${ }^{68}$ The diagnosis of PsA can be relatively easy to establish in patients with a known diagnosis of skin psoriasis. However, skin psoriasis can be so subtle that it goes unnoticed for a considerable period of time. So it can be very valuable to look for the presence of skin lesions in the natal cleft, scalp, and behind the ears. Similarly, it can be quite challenging to diagnose PsA sine psoriasis, which can be present in up to $15 \%$ of cases; in this scenario, typical clinical features (eg, dactylitis, asymmetrical arthritis, enthesitis) and/or typical radiographic features (such as fluffy periostitis, lysis of terminal phalanges, pencil-in-cup appearance, gross destruction of isolated joint, ankylosis, and spondylitis) in the presence of negative rheumatoid factor can help to make this diagnosis.

CASPAR are validated classification criteria, and have the potential to be used for the diagnosis of PsA. ${ }^{69}$ They allow making the diagnosis of PsA even in the presence of low rheumatoid factor positivity, and because of the inclusion of dactylitis and enthesitis, in the absence of florid arthritis (Table 1). With such a high degree of sensitivity (0.91) and specificity (0.98), the CASPAR criteria are very simple to use. 
Table I The CASPAR criteria for psoriatic arthritis

Inflammatory articular disease (joint, spine, or entheseal) with $\geq 3$ points from the following categories

I. Evidence of current psoriasis, a personal history of psoriasis, or a family history of psoriasis

(Current psoriasis is assigned a score of 2; all other features are assigned a score of I)

2. Typical psoriatic nail dystrophy, including onycholysis, pitting, and hyperkeratosis observed on current physical examination (I point)

3. A negative test result for the presence of rheumatoid factor by any method except latex (I point)

4. Either current dactylitis, defined as swelling of an entire digit, or a history of dactylitis recorded by a rheumatologist (I point)

5. Radiographic evidence of juxta-articular new bone formation appearing as ill-defined ossification near joint margins (but excluding osteophyte formation) on plain radiographs of the hand or foot (I point)

\section{Patient-focused perspectives}

PsA is a chronic disease, characterized by pain and stiffness, and can be potentially physically disabling. Research has clearly indicated that chronic arthritis and other musculoskeletal disorders affect multiple life domains, such as long-term disability, relationships, sexual function, work impairment, restricted activity, and more medical visits. ${ }^{70,71}$ Moreover, compared to patients with osteoarthritis, pain in inflammatory arthritis increases with age and duration of disease, subsequently leading to impaired quality of life (QOL). ${ }^{72}$

QOL is the "individual's perceptions of their position in life in the context of the culture and value systems in which they live, and in relation to their goals, expectations, and concerns". ${ }^{73} \mathrm{QOL}$ is an umbrella term, and it encompasses physical, mental, and social well-being. Contrary to professionally developed outcome scores, QOL is a personal experience, and this clearly should be described by patients themselves. A recent literature review has shown that in pharmacological trials involving patients with inflammatory arthritis, psychosocial outcome domains, such as fatigue, coping, and sleep disturbance, are underreported..$^{74}$ However, research has clearly demonstrated that these patient-derived subjective outcome measures are quite important to these patients. ${ }^{75,76}$ A very recent report has shown that health-related QOL is much diminished in patients with PsA and RA compared with age and sex-matched controls, and very reassuringly, improvements have been described in response to therapy in both physical and mental health components of the Short Form (36) Health Survey (SF-36) in PsA. ${ }^{77}$ The most commonly used Health Assessment Questionnaire (HAQ) mainly addresses general physical impairment, and there is omission of pain-related outcome domains. Although these scores are self-reported or in other words subjective, when combined with a clinical assessment, a reasonably objective assessment of disability can be obtained.

We believe that clinical care of patients with rheumatic diseases should be focused not only on more objective measures, such as clinical examination and laboratory measures, but also on the subjective outcomes that seem more important to them, which are firstly pain, secondly fatigue, and thirdly impaired morning function, and the combined effect of all of these on QOL. Moreover, these outcomes should ideally be evaluated individually after taking into account the patient's total lifestyle, and this furthers the value of a multidisciplinary team approach in managing patients with PsA.

\section{Current and emerging treatment options}

Following systematic reviews of the literature, both the Group for Research and Assessment of Psoriasis and Psoriatic Arthritis (GRAPPA) and the European League Against Rheumatism (EULAR) have published recommendations for the treatment of PsA. The GRAPPA treatment guidelines, which will shortly be revised, categorize treatment on the basis of disease characteristics, in particular organ involvement. ${ }^{78}$ The EULAR treatment recommendations, which focus only on musculoskeletal involvement, propose overarching principles as well as ten treatment recommendations based on the literature. ${ }^{79}$ While symptomatic measures including analgesics, nonsteroidal anti-inflammatory drugs, and local corticosteroid injections can be sufficient in some patients, it is recommended that in patients with active disease (particularly those with many swollen joints, structural damage in the presence of inflammation, high ESR/C-reactive protein, and/or clinically relevant extra-articular manifestations), treatment with disease-modifying antirheumatic drugs (DMARDs) should be considered at an early stage.

\section{Disease-modifying antirheumatic drugs in PsA}

While most rheumatologists would use methotrexate (MTX) as the DMARD of first choice in patients with PsA, this decision is difficult to support based on the evidence in the literature. Up until recently, there had been only three randomized controlled trials (RCTs) of MTX in PsA and a total of 93 patients studied. Results suggested some efficacy on joints and skin, but findings were inconclusive, in particular in view of small study numbers. ${ }^{80-82}$ Recently, Kingsley and colleagues reported the results of the Methotrexate in PsA study, a 6-month RCT comparing MTX with placebo in 
221 active PsA patients. ${ }^{83}$ The trial took several years to complete, and results showed no evidence that MTX improved synovitis compared to placebo. There were, however, some design issues with this trial, including that the maximum dose of MTX was held at $15 \mathrm{mg}$ per week, which would be considered suboptimal by many. In addition, the primary outcome measure was the dichotomous PsA Response Criteria (PsARC), which appear to poorly differentiate between active treatment and placebo.

In relation to other disease-modifying treatments, there have been seven RCTs involving sulfasalazine, ${ }^{84-90}$ one involving leflunomide, and three involving cyclosporin..$^{90-93}$ All of these studies showed some efficacy on joint disease, with skin efficacy also demonstrated for cyclosporin. No radiographic data were collected.

The GRAPPA treatment guidelines suggest that the choice of DMARDs in PsA should depend on the particular aspects of disease the patient is affected with, and in this the EULAR recommendations also agree. For example, in patients with active PsA and clinically relevant psoriasis, a DMARD that also improves psoriasis, such as MTX, should be preferred. At least a 3-month trial of a DMARD at maximal tolerated doses (eg, MTX $25 \mathrm{mg} /$ week) is required before deciding that a patient is a responder or a nonresponder.

\section{Anti-TNF therapy}

As per the EULAR recommendations, in patients with active arthritis and an inadequate response to at least one DMARD such as MTX, treatment with a TNF inhibitor (TNFi) should be considered. ${ }^{79}$ Indeed, with no evidence to support DMARDs in patients with predominant spinal disease and little or no evidence to support DMARDs for patients with major entheseal or dactylitic involvement, the introduction of a TNFi without prior DMARD could be justified. RCTs in PsA confirm that TNFis are efficacious for joint disease using both the PsARC and the American College of Rheumatology (ACR)-20 response measures, but more importantly also the more clinically meaningful ACR-50 measure. The risk ratio for an ACR-50 response at 12-weeks, as compared to placebo for the RCTs combined, is 10.9. TNFis are also substantially efficacious on skin manifestations, with the risk ratio for a Psoriasis Area and Severity Index 75 response in combined studies at 17 in favor of active treatment. ${ }^{90}$ For other features, such as enthesitis or dactylitis, efficacy has been demonstrated in RCTs, but only as secondary end points and with a variety of instruments used to record entheseal or dactylitic involvement in the individual RCTs. Nonetheless, trials do suggest a significant improvement in these features, leading to the conclusion that TNFis may indeed be efficacious for these disease manifestations as well. All TNFi drugs are effective in PsA, and to date there have been no published head-to-head trials of different TNFi use in PsA to draw any firm conclusions.

For patients with predominant axial disease, there is as yet no information available on efficacy of TNFi in any of the published RCTs. Some efficacy has been shown in observational cohorts with one study from Olivieri et al confirming a significant improvement in Bath Ankylosing Spondylitis Disease Activity Index and Bath Ankylosing Spondylitis Functional Index in 107 PsA patients commencing TNFi treatment. ${ }^{94}$

\section{Switching TNFis}

Registry data has shown that 1-year drug survival for the first TNFi ranged between 0.82 and 0.87 . Following a second biologic, 1-year survival reduces but is still reasonable, ranging between 0.74 and $0.8 .^{95,96}$ In relation to efficacy, in a prospective observational study, patients who had received prior biologics improved at 12 months of therapy, but improvement was less marked compared to a biologic-naive group. ${ }^{97}$

\section{TNFi failures}

If a patient continues to have moderate or high disease activity after 3 months of TNFi therapy, either due to a lack or loss of benefit, switching to another TNFi is recommended. Approximately $20 \%$ of patients either do not respond to or are intolerant of TNFi therapy. In this situation, a number of options can be considered, including combination therapy, other non-TNFi biologic therapies, and perhaps some newer therapeutic strategies. In patients who fail TNFi therapy, there is some accumulating evidence that abatacept or ustekinumab may be worthwhile considering.

\section{Combination systemic therapies}

Daly et al published a literature review relating to combination therapy in PsA, which after some exclusions yielded a total of 21 articles. ${ }^{98}$ The majority of these studies were related to combinations of a TNFi and MTX. In general, these studies showed that a combination of a TNFi with MTX had no apparent effect on clinical outcomes, though there was a suggestion that TNFi drug survival was enhanced in patients with concomitant MTX usage. In most of these studies, the effect of combination therapy was not the primary outcome, with the TNFi being added to baseline MTX in a subset of patients and outcome compared in a secondary analysis with outcome in those patients not on baseline MTX. 
The requirement, therefore, remains for a well-constructed RCT that examines the use of MTX alone, compared with a TNFi alone, compared with a combination.

Other combinations examined included that of cyclosporin and MTX in three studies. The most recently published confirmed efficacy of a combination versus patients remaining on baseline MTX only. However, a large number of patients in the combination arm were withdrawn due to side effects, nausea being the most common.

\section{Non-TNF biologic therapies}

The use of abatacept was recently examined in a 6-month RCT in 170 PsA patients. Compared with placebo, improvements were significantly greater for patients treated with abatacept using doses of either $10 \mathrm{mg} / \mathrm{kg}$ or 2 initial doses of $30 \mathrm{mg} / \mathrm{kg}$ followed by $10 \mathrm{mg} / \mathrm{kg}$. All abatacept regimens resulted in improved MRI, HAQ, and SF-36 scores with the $10 \mathrm{mg} / \mathrm{kg}$ dose showing the greatest change. ${ }^{99}$

Ustekinumab, which is the human IL-12/23 monoclonal antibody, has been examined in two studies, with the initial 2009 report in 146 patients showing that $42 \%$ of patients achieved the primary end point (ACR-20 response). ${ }^{100}$ In the results of a further RCT (PSummit 1, as of yet published in abstract form only), an ACR-20 response was achieved at 24 weeks by $49.5 \%$ of patients on ustekinumab $90 \mathrm{mg}$ and by $42.4 \%$ of patients on $45 \mathrm{mg}$. There was also a $50 \%$ improvement in entheseal scores and a $70 \%$ improvement in dactylitis scores in patients on the higher dosage. ${ }^{101}$

In relation to other non-TNF biologics, there are as yet no published trial data on either tocilizumab or rituximab. In a recent observational study, some efficacy with rituximab was suggested. Recent studies have highlighted the possible importance of the IL-17 pathway in the pathogenesis of PsA. ${ }^{102}$ RCTs using IL-17 inhibitors will shortly be under way, with the results eagerly awaited.

Results of studies using novel small molecules in PsA are also awaited. These novel nonbiologic therapies, which target intracellular signaling pathways, have been shown to be efficacious in RA. A recent RCT examined the role of apremilast, which specifically targets phosphodiesterase 4, in 204 patients with active PsA. At the end of 12 weeks of treatment, $23.5 \%$ of patients receiving $20 \mathrm{mg}$ of apremilast twice daily and $35.8 \%$ of those receiving $40 \mathrm{mg}$ twice daily achieved an ACR-20 response. Adverse events were not uncommon, but consistent with incidence reported with other phosphodiesterase 4 inhibitors. The majority of adverse events occurred with the $40 \mathrm{mg}$ dose and were of mild or moderate severity. Two severe infections occurred with apremilast
$40 \mathrm{mg}$ daily, but none resulted in study discontinuation. ${ }^{103}$ Finally, in patients with RA, the effectiveness of molecules that inhibit signal transduction of cytokines (anti-janus kinase) has been proven; however, their usefulness in PsA remains unknown.

\section{Prognosis of psoriasis arthritis}

Precise prediction of overall prognosis of PsA is difficult, because of significant individual variations of joint and skin manifestations. Generally, the prognosis will depend on the extent and severity of joint and skin disease, female sex, younger age, and certain HLA types, for example, HLA-B*27, which are associated with worse prognosis. Clinical predictors for disease progression also included more than five swollen joints and high medication level, particularly the use of steroids at presentation. ${ }^{104}$

\section{Disclosure}

The authors report no conflicts of interest in this work.

\section{References}

1. Gladman DD, Antoni C, Mease P, Clegg DO, Nash P. Psoriatic arthritis: epidemiology, clinical features, course, and outcome. Ann Rheum Dis. 2005;64 Suppl 2:ii14-ii17.

2. Gelfand JM, Gladman DD, Mease PJ, et al. Epidemiology of psoriatic arthritis in the population of the United States. J Am Acad Dermatol. 2005;53:573.

3. Moll JMH, Wright V. Familial occurrence of psoriatic arthritis. Ann Rheum Dis. 1973;32:181-201.

4. Rahman P, Elder JT. Genetic epidemiology of psoriasis and psoriatic arthritis. Ann Rheum Dis. 2005;64 Suppl 2:37-39.

5. Myers A, Kay LJ, Lynch SA, Walker DJ. Recurrence risk for psoriasis and psoriatic arthritis within sibships. Rheumatology (Oxford). 2005;44:773-776

6. Winchester R. Genetics of psoriasis and psoriatic arthritis. In: Ritchlin CT, FitzGerald O, editors. Psoriatic and Reactive Arthritis: A Companion to Rheumatology. Amsterdam: Elsevier; 2007:65-80.

7. Winchester R. The major histocompatibility complex. In: Rich RR, Fleisher TA, Shearer WT, Schroeder H, Frew AJ, Weyand CM, editors. Clinical Immunology: Principles and Practice. London: Elsevier; 2012:68-76.

8. Robinson J, Mistry K, McWilliam H, Lopez R, Parham P, Marsh SGE. The IMGT/HLA database. Nucleic Acids Res. 2011;39: D1171-D1176

9. Winchester R, Minevich G, Steshenko V, et al. HLA associations reveal genetic heterogeneity in psoriatic arthritis and in the psoriasis phenotype. Arthritis Rheum. 2012;64:1134-1144.

10. Eder L, Chandran V, Pellet F, et al. Human leucocyte antigen risk alleles for psoriatic arthritis among patients with psoriasis. Ann Rheum Dis. 2012;71:50-55.

11. Tiilikainen A, Lassus A, Karvonen J, Vartiainen P, Julin M. Psoriasis and HLA-Cw6. Br J Dermatol. 1980;102:179-184.

12. Henseler T, Koch F, Westphal E, et al. Presence of HLA-DR7 in type I psoriasis. J Invest Dermatol. 1992;98:607.

13. Elder JT. PSORS1: linking genetics and immunology. $J$ Invest Dermatol. 2006;126:1205-1206.

14. Nair RP, Stuart PE, Nistor I, et al. Sequence and haplotype analysis supports HLA-C as the psoriasis susceptibility 1 gene. Am J Hum Genet. 2006;78:827-851. 
15. Murray C, Mann DL, Gerber LN, et al. Histocompatibility alloantigens in psoriasis and psoriatic arthritis. Evidence for the influence of multiple genes in the major histocompatibility complex. J Clin Invest. 1980;66:670-675.

16. Barton AC. Genetic epidemiology. Psoriatic arthritis. Arthritis Res. 2002;4:247-251

17. Eastmond CJ. Psoriatic arthritis. Genetics and HLA antigens. Baillieres Clin Rheumatol. 1994;8:263-276.

18. Szczerkowska Dobosz A, Rebala K, Szczerkowska Z, Nedoszytko B. HLA-C locus alleles distribution in patients from northern Poland with psoriatic arthritis - preliminary report. Int J Immunogenet. 2005;32: 389-391.

19. Gonzalez S, Martinez-Borra J, Lopez-Vazquez A, Garcia-Fernandez S, Torre-Alonso JC, Lopez-Larrea C. MICA rather than MICB, TNFA, or HLA-DRB1 is associated with susceptibility to psoriatic arthritis. J Rheumatol. 2002;29:973-978.

20. Gladman DD, Cheung C, Ng CM, Wade JA. HLA-C locus alleles in patients with psoriatic arthritis (PsA). Hum Immunol. 1999;60: 259-261.

21. Al-Heresh AM, Proctor J, Jones SM, et al. Tumour necrosis factoralpha polymorphism and the HLA-Cw*0602 allele in psoriatic arthritis. Rheumatology (Oxford). 2002;41:525-530.

22. Gonzalez S, Brautbar C, Martinez-Borra J, et al. Polymorphism in MICA rather than HLA-B/C genes is associated with psoriatic arthritis in the Jewish population. Hum Immunol. 2001;62:632-638.

23. Ansell B, Beeson M, Hall P, Bedford P, Woo P. HLA and juvenile psoriatic arthritis. Br J Rheumatol. 1993;32:836-837.

24. Brewerton DA, Caffrey M, Nicholls A, Walters D, James DC. HL-A 27 and arthropathies associated with ulcerative colitis and psoriasis. Lancet 1974;1:956-958.

25. Zachariae H, Overgaard Petersen H, Kissmeyer Nielsen F, Lamm L. HL-A antigens in pustular psoriasis. Dermatologica. 1977;154:73-77.

26. Armstrong RD, Panayi GS, Welsh KI. Histocompatibility antigens in psoriasis, psoriatic arthropathy and ankylosing spondylitis. Ann Rheum Dis. 1983;42:142-146.

27. Gladman DD, Farewell VT, Kopciuk KA, Cook RJ. HLA markers and progression in psoriatic arthritis. J Rheumatol. 1998;25:730-733.

28. Trabace S, Cappellacci S, Ciccarone P, Liaskos S, Polito R, Zorzin L. Psoriatic arthritis: a clinical, radiological and genetic study of 58 Italian patients. Acta Derm Venereol Suppl (Stockh). 1994;186: 69-70.

29. Espinoza LR, Vasey FB, Oh JH, Wilkinson R, Osterland CK. Association between HLA-Bw38 and peripheral psoriatic arthritis. Arthritis Rheum. 1978;21:72-75.

30. Lund O, Nielsen M, Kesmir C, et al. Definition of supertypes for HLA molecules using clustering of specificity matrices. Immunogenetics. 2004;55:797-810.

31. Rammensee H, Bachmann J, Emmerich NP, Bachor OA, Stevanovic S SYFPEITHI: database for MHC ligands and peptide motifs Immunogenetics. 1999;50:213-219.

32. Marsh SGE, Parham P, Barber LD. The HLA Facts Book. San Diego: Academic Press; 2000

33. Benjamin R, Parham P. Guilt by association: HLA-B27 and ankylosing spondylitis. Immunol Today. 1990;11:137-142.

34. Sobao Y, Tsuchiya N, Takiguchi M, Tokunaga K. Overlapping peptidebinding specificities of HLA-B27 and B39: evidence for a role of peptide supermotif in the pathogenesis of spondylarthropathies. Arthritis Rheum. 1999;42:175-181.

35. Yamaguchi A, Tsuchiya N, Mitsui H, et al. Association of HLA-B39 with HLA-B27-negative ankylosing spondylitis and pauciarticular juvenile rheumatoid arthritis in Japanese patients. Evidence for a role of the peptide-anchoring B pocket. Arthritis Rheum. 1995;38:1672-1677.

36. Colbert RA. The immunobiology of HLA-B27: variations on a theme. Curr Mol Med. 2004;4:21-30.

37. Bowness P, Ridley A, Shaw J, et al. Th17 cells expressing KIR3DL2+ and responsive to HLA-B27 homodimers are increased in ankylosing spondylitis. J Immunol. 2011;186:2672-2680.
38. Feng BJ, Sun LD, Soltani-Arabshahi R, et al. Multiple loci within the major histocompatibility complex confer risk of psoriasis. PLoS Genet. 2009;5:e1000606.

39. Queiro R, Sarasqueta C, Belzunegui J, Gonzalez C, Figueroa M, Torre-Alonso JC. Psoriatic spondyloarthropathy: a comparative study between HLA-B27 positive and HLA-B27 negative disease. Semin Arthritis Rheum. 2002;31:413-418.

40. Gladman D, Anhorn K, Schachter R, Mervart H. HLA antigens in psoriatic arthritis. J Rheumatol. 1986;13:586-592.

41. Gladman DD, Farwell VT. The role of HLA antigens as indicators of disease progression in psoriatic arthritis. Multivariate relative risk model. Arthritis Rheum. 1995;38:845-850.

42. Queiro-Silva R, Torre-Alonso JC, Tinture-Eguren T, Lopez-Lagunas I. The effect of HLA-DR antigens on the susceptibility to, and clinical expression of psoriatic arthritis. Scand J Rheumatol. 2004;33: 318-322.

43. Grubić Z, Perić P, Eeèuk-Jelicić E, et al. The MICA-A4 triplet repeats polymorphism in the transmembrane region confers additional risk for development of psoriatic arthritis in the Croatian population. Eur $J$ Immunogenet. 2004;31:93-98.

44. Ho PY, Barton A, Worthington J, Thomson W, Silman AJ, Bruce IN. HLA-Cw6 and HLA-DRB1*07 together are associated with less severe joint disease in psoriatic arthritis. Ann Rheum Dis. 2007;66:807-811.

45. Haroon M, Giles JT, Winchester R, Fitzgerald O. Role of particular class I MHC haplotypes in determining different traits within the psoriatic arthritis phenotype. Available from: http://www.rheumatology. org/apps/MyAnnualMeeting/ExploreMeeting/AbstractDetail?abstractI $\mathrm{d}=30755$. Accessed March 22, 2013.

46. Winchester R, Itescu S. HIV and the rheumatic diseases. In:PJ Maddison PJ, Isenberg DA, Woo P, Glass DN, editors. Oxford Textbook of Rheumatology. Oxford: Oxford University Press; 1993:560-573.

47. Tassiulas I, Duncan SR, Centola M, Theofilopoulos AN, Boumpas DT. Clonal characteristics of $\mathrm{T}$ cell infiltrates in skin and synovium of patients with psoriatic arthritis. Hum Immunol. 1999;60:479-491.

48. Costello P, Bresnihan B, O’Farrelly C, FitzGerald O. Predominance of CD8+ T lymphocytes in psoriatic arthritis. J Rheumatol. 1999;26: 1117-1124.

49. Costello PJ, Winchester RJ, Curran SA, et al. Psoriatic arthritis joint fluids are characterized by CD8 and CD4 T cell clonal expansions appear antigen driven. J Immunol. 2001;166:2878-2886.

50. Curran SA, FitzGerald OM, Costello PJ, et al. Nucleotide sequencing of psoriatic arthritis tissue before and during methotrexate administration reveals a complex inflammatory $\mathrm{T}$ cell infiltrate with very few clones exhibiting features that suggest they drive the inflammatory process by recognizing autoantigens. J Immunol. 2004;172:1935-1944.

51. Pitzalis C, Cauli A, Pipitone N, et al. Cutaneous lymphocyte antigenpositive T lymphocytes preferentially migrate to the skin but not to the joint in psoriatic arthritis. Arthritis Rheum. 1996;39:137-145.

52. Veale DJ, Barnes L, Rogers S, FitzGerald O. Immunohistochemical markers for arthritis in psoriasis. Ann Rheum Dis. 1994;53:450-454.

53. Kruithof E, Baeten D, De Rycke L, et al. Synovial histopathology of psoriatic arthritis, both oligo- and polyarticular, resembles spondyloarthropathy more than it does rheumatoid arthritis. Arthritis Res Ther. 2005;7:R569-R580

54. Liu Y, Helms C, Liao W, et al. A genome-wide association study of psoriasis and psoriatic arthritis identifies new disease loci. PLoS Genet. 2008;4:e1000041.

55. Bowes J, Barton A. The genetics of psoriatic arthritis: lessons from genome-wide association studies. Discov Med. 2010;10:177-183.

56. Sherlock JP, Joyce-Shaikh B, Turner SP, et al. IL-23 induces spondyloarthropathy by acting on ROR-gammat+ CD3+CD4-CD8-entheseal resident T cells. Nat Med. 2012;18:1069-1076.

57. Taylor W, Gladman D, Helliwell P, Marchesoni A, Mease P, Mielants H. Classification criteria for psoriatic arthritis: development of new criteria from a large international study. Arthritis Rheum. 2006;54: 2665-2673.

58. Olivieri I, Barozzi L, Favaro L, et al. Dactylitis in patients with seronegative spondylarthropathy: assessment by ultrasonography and magnetic resonance imaging. Arthritis Rheum. 1996;39:1524-1528. 
59. Olivieri I, Padula A, Scarano E, Scarpa R. Dactylitis or "sausageshaped" digit. J Rheumatol. 2007;34;1217-1222.

60. Moll JMH, Wright V. Psoriatic arthritis. Semin Arthritis Rheum. 1973;3:55-78.

61. Brockbank JE, Stein M, Schentag CT, Gladman DD. Dactylitis in psoriatic arthritis: a marker for disease severity? Ann Rheum Dis. 2005;64:188-190.

62. Moll JMH, Wright V. Psoriatic arthritis. Semin Arthritis Rheum. 1973;3: 55-78.

63. Helliwell PS, Porter G, Taylor WJ. Polyarticular psoriatic arthritis is more like oligoarticular psoriatic arthritis, than rheumatoid arthritis. Ann Rheum Dis. 2007;66:113-117.

64. Sieper J, van der Heijde D, Landewé R, et al. New criteria for inflammatory back pain in patients with chronic back pain: a real patient exercise by experts from the Assessment of Spondyloarthritis International Society (ASAS). Ann Rheum Dis. 2009;68:784-788.

65. McGonagle D, Lories RJ, Tan AL, Benjamin M. The concept of a "synovio-entheseal complex" and its implications for understanding joint inflammation and damage in psoriatic arthritis and beyond. Arthritis Rheum. 2007;56:2482-2491.

66. Alenius GM, Berglin E, Rantapaa Dahlqvist S. Antibodies against cyclic citrullinated peptide (CCP) in psoriatic patients with or without joint inflammation. Ann Rheum Dis. 2006;65:398-400.

67. Abdel Fattah NS, Hassan HE, Galal ZA, El Okda el SE. Assessment of anti-cyclic citrullinated peptide in psoriatic arthritis. BMC Res Notes. 2009;2:44.

68. Resnick DL. Psoriatic arthritis. In: Diagnosis of Bone and Joint Disorders, 2nd ed. Philadelphia: WB Saunders: 1988:1171-1199.

69. Congi L, Roussou E. Clinical application of the CASPAR criteria for psoriatic arthritis compared to other existing criteria. Clin Exp Rheumatol. 2010;28:304-310.

70. Badley EM, Rasooly I, Webster GK. Relative importance of musculoskeletal disorders as a cause of chronic health problems, disability, and health care utilization: findings from the 1990 Ontario Health Survey. J Rheumatol. 1994;21:505-514.

71. Hill J, Bird H, Thorpe R. Effects of rheumatoid arthritis on sexual activity and relationships. Rheumatology (Oxford). 2003;42:280-286.

72. Jakobsson U, Hallberg IR. Pain and quality of life among older people with rheumatoid arthritis and/or osteoarthritis: a literature review. J Clin Nurs. 2002;11:430-443.

73. [No authors listed]. Study protocol for the World Health Organization project to develop a quality of life assessment instrument (WHOQOL). Qual Life Res. 1993;2:153-159.

74. Kalyoncu U, Dougados M, Daurès J, Gossec L. Reporting of patientreported outcomes in recent trials in rheumatoid arthritis: a systematic literature review. Ann Rheum Dis. 2009;68:183-190.

75. McPherson KM, Brander P, Taylor WJ, McNaughton HK. Living with arthritis - what is important? Disabil Rehabil. 2001;23:706-721.

76. Carr A, Hewlett S, Hughes R, et al. Rheumatology outcomes: the patient's perspective. J Rheumatol. 2003;30:880-883.

77. Strand V, Sharp V, Koenig AS, et al. Comparison of health-related quality of life in rheumatoid arthritis, psoriatic arthritis and psoriasis and effects of etanercept treatment. Ann Rheum Dis. 2012;71: $1143-1150$

78. Ritchlin CT, Kavanaugh A, Gladman DD, et al. Treatment recommendations for psoriatic arthritis. Ann Rheum Dis. 2009;68:1387-1394.

79. Gossec L, Smolen J, Gaujoux-Viala C, et al. European League Against Rheumatism recommendations for the management of psoriatic arthritis with pharmacological therapies. Ann Rheum Dis. 2012;71: 4-12.

80. Black RL, O'brien WM, Vanscott EJ, Auerbach R, Eisen AZ, Bunim JJ. Methotrexate therapy in psoriatic arthritis; double-blind study on 21 patients. JAMA. 1964;189:743-747.

81. Scarpa R, Peluso R, Atteno M, et al. The effectiveness of a traditional therapeutical approach in early psoriatic arthritis: results of a pilot randomised 6-month trial with methotrexate. Clin Rheumatol. 2008;27:823-826.
82. Willkens RF, Williams HJ, Ward JR, et al. Randomized, double-blind, placebo controlled trial of low-dose pulse methotrexate in psoriatic arthritis. Arthritis Rheum. 1984;27:376-381.

83. Kingsley GH, Kowalczyk A, Taylor H, et al. A randomized placebocontrolled trial of methotrexate in psoriatic arthritis. Rheumatology (Oxford). 2012;51:1368-1377.

84. Clegg DO, Reda DJ, Mejias E, et al. Comparison of sulfasalazine and placebo in the treatment of psoriatic arthritis. A Department of Veterans Affairs Cooperative Study. Arthritis Rheum. 1996;39:2013-2020.

85. Combe B, Goupille P, Kuntz JL, Tebib J, Lioté F, Bregeon C. Sulphasalazine in psoriatic arthritis: a randomized, multicentre, placebo-controlled study. Br J Rheumatol. 1996;35:664-668.

86. Dougados M, vam der Linden S, Leirisalo-Repo M, et al. Sulfasalazine in the treatment of spondylarthropathy. A randomized, multicenter, doubleblind, placebo controlled study. Arthritis Rheum. 1995;38:618-627.

87. Farr M, Kitas GD, Waterhouse L, Jubb R, Felix-Davies D, Bacon PA. Sulphasalazine in psoriatic arthritis: a double-blind placebo-controlled study. Br J Rheumatol. 1990;29:46-49.

88. Fraser SM, Hopkins R, Hunter JA, Neumann V, Capell HA, Bird HA. Sulphasalazine in the management of psoriatic arthritis. BrJ Rheumatol. 1993;32:923-925.

89. Gupta AK, Grober JS, Hamilton TA, et al. Sulfasalazine therapy for psoriatic arthritis: a double blind, placebo controlled trial. J Rheumatol. 1995;22:894-898.

90. Salvarani C, Macchioni P, Olivieri I, et al. A comparison of cyclosporine, sulfasalazine, and symptomatic therapy in the treatment of psoriatic arthritis. J Rheumatol. 2001;28:2274-2282.

91. Kaltwasser JP, Nash P, Gladman D, et al. Efficacy and safety of leflunomide in the treatment of psoriatic arthritis and psoriasis: a multinational, double-blind, randomized, placebo-controlled clinical trial. Arthritis Rheum. 2004;50:1939-1950.

92. Ash Z, Gaujoux-Viala C, Gossec L, et al. A systematic literature review of drug therapies for the treatment of psoriatic arthritis: current evidence and meta-analysis informing the EULAR recommendations for the management of psoriatic arthritis. Ann Rheum Dis. 2012;71:319-326.

93. Fraser AD, van Kuijk AW, Westhovens R, et al. A randomised, double blind, placebo controlled, multicentre trial of combination therapy with methotrexate plus ciclosporin in patients with active psoriatic arthritis. Ann Rheum Dis. 2005;64:859-864.

94. Olivieri I, de Portu S, Salvarani C, et al. The psoriatic arthritis cost evaluation study: a cost-of-illness study on tumour necrosis factor inhibitors in psoriatic arthritis patients with inadequate response to conventional therapy. Rheumatology (Oxford). 2008;47: 1664-1670.

95. Saad AA, Ashcroft DM, Watson KD, Hyrich KL, Noyce PR, Symmons DP. Persistence with anti-tumour necrosis factor therapies in patients with psoriatic arthritis: observational study from the British Society of Rheumatology Biologics Register. Arthritis Res Ther. 2009;11:R52.

96. Gomez-Reino JJ, Carmona L. Switching TNF antagonists in patients with chronic arthritis: an observational study of 488 patients over a four-year period. Arthritis Res Ther. 2006;8:R29.

97. Mease P, Fleischmann R, Deodhar A, et al. Effect of certolizumab pegol on signs and symptoms in patients with psoriatic arthritis: 24 week results of a phase 3 double blind randomized placebo-controlled study (RAPID-PsA). Ann Rheum Dis. 2012;71:S150.

98. Daly M, Alikhan A, Armstrong AW. Combination systemic therapies in psoriatic arthritis. J Dermatolog Treat. 2011;22:276-284.

99. Mease P, Genovese MC, Gladstein G, et al. Abatacept in the treatment of patients with psoriatic arthritis: results of a six-month, multicenter, randomized, double-blind, placebo-controlled, phase II trial. Arthritis Rheum. 2011;63:939-948.

100. Gottlieb A, Menter A, Mendelsohn A, et al. Ustekinumab, a human interleukin 12/23 monoclonal antibody, for psoriatic arthritis: randomised, double-blind, placebo-controlled, crossover trial. Lancet. 2009;373:633-640. 
101. McInnes I, Kavanaugh A, Gottlieb A, et al. Ustekinumab in patients with active psoriatic arthritis: Results of the phase 3, multicenter, double-blind, placebo-controlled PSUMMIT I study. Ann Rheum Dis. 2012;71:S107.

102. Schett G, Wollenhaupt J, Papp K, et al. Oral apremilast in the treatment of active psoriatic arthritis: Results of a multicenter, randomized, double-blind, placebo-controlled study. Arthritis Rheum. 2012;64: 3156-3167.
103. Schett G, Wollenhaupt J, Papp K, et al. Oral apremilast in the treatment of active psoriatic arthritis: results of a multicenter, randomized, double-blind, placebo-controlled study. Arthritis Rheum. 2012;64: 3156-3167.

104. Gladman DD, Farewell VT, Nadeau C. Clinical indicators of progression in psoriatic arthritis: multivariate relative risk model. J Rheumatol. 1995;22:675-679.

\section{Publish your work in this journal}

Psoriasis: Targets and Therapy is international, peer-reviewed, open access journal focusing on psoriasis, nail psoriasis, psoriatic arthritis and related conditions, identification of therapeutic targets and the optimal use of integrated treatment interventions to achieve improved outcomes and quality of life. The manuscript management system

\section{Dovepress}

is completely online and includes a very quick and fair peer-review system. Visit http://www.dovepress.com/testimonials.php to read real quotes from published authors. 